\title{
Research on the Development of Characteristic Tourism Towns in Northern Anhui under Rural Revitalization
}

\author{
Maolin Zhao*, Suyu Liu \\ School of Economics, Anhui University of Finance and Economics, Bengbu, 233030, China \\ *Corresponding author: Maolin Zhao (Email: zhaomaol1345@163.com)
}

\begin{abstract}
Characteristic towns are the continuation and development of the construction of "small towns", and have become an important node of the development of "urban-rural integration". Characteristic tourism town is one of the important models of rural tourism development. It plays an important role in promoting the solution of "Three rural issues", increasing farmers' opportunities for entrepreneurship and employment, improving farmers' income, building a beautiful countryside and finally realizing rural revitalization. The restrictive factors and main problems of the development of characteristic tourism towns in Northern Anhui are: single business model and shallow cultural excavation level. The development foundation is relatively weak, and the industrial products are not closely related. The essence of cultural characteristics is not fully reflected, which needs to be deeply excavated. Through the analysis, the following development ideas and countermeasures of characteristic tourism towns in Northern Anhui are formed: first, give full play to the resources with the most comparative advantages and take the road of characteristic development. Second, make leisure tourism closely related to the characteristic industries and products of small towns. Third, deeply excavate and fully absorb traditional culture, and create a new idea of developing characteristic tourism towns in Northern Anhui with the combination of culture and tourism. Fourth, actively explore the new mode of "Internet plus tourism".
\end{abstract}

Keywords: Characteristic towns, Characteristic road, Industrial chain, Traditional culture.

\section{Introduction}

The concept of characteristic towns originated from Yunqi town in Zhejiang Province in 2014. In the outline of the 13th Five-Year Plan for national economic and social development of the People's Republic of China in 2016, it was carried out the task of accelerating the development of small and medium-sized cities and characteristic towns, developing small towns with distinctive characteristics, city-industry integrated and charming according to local conditions [1]. A boom in the construction of characteristic towns has arisen all over the country. Represented by Yunqi town in Zhejiang Province, characteristic towns have developed rapidly throughout the country with the support of national policies. Before that, the state advocated the new urbanization strategy, and the development of small towns is also a hot spot. Characteristic towns are the continuation and development of the construction of "small towns", as well as the continuation and important development node of the development of "urban-rural integration" [2]. Characteristic town refers to a small town with tourism resources gathered in a certain area, covering leisure and vacation tourism, business logistics circulation, modern production and manufacturing, education and science and technology gathering, traditional culture development, beautiful countryside and livable characteristics [3].

The implementation of the Rural Revitalization Strategy was put forward in the report of the 19th National Congress of the Communist Party of China. The report pointed out that the problem of agricultural and rural peasants is a fundamental issue related to the national economy and the individuals' livelihood, we must always take the solution of "Three rural issues" as the top priority of the work of the whole party. It is necessary to adhere to the priority development of agriculture and rural areas, establish and improve the institutional mechanisms and policy systems for the integration of urban and rural development in accordance with the general requirements of industrial prosperity, ecological livability, civilize druralcustoms, effective governance, and affluent life, as well as accelerate the modernization of agriculture and rural areas [4]. In the new historical period, the spiritual and cultural needs of the people are becoming more and more diversified, personalized and qualitative, which also indirectly promotes the development of China's tourism industry. Tourism industry has increasingly become one of the important industries in the national economic system. Under the background of Rural Revitalization Strategy, rural tourism, as the "adhesive" integrating the development of various industries, the integrated development of agricultural culture, processing industry, sports and tourism will effectively integrate the resources of various industries such as agriculture, industry and service industry, improve the quality of various industriesfurtherly and promote the connotative development of various industries. The characteristic tourism town has become one of the important modes of rural tourism development. It plays a very important role in promoting the solution of the "Three rural issues", strengthening the development of agricultural basic industries, expanding the industrial chain, increasing the opportunities for farmers to start a business and find employment nearby, improving farmers' income, building a beautiful countryside and realizing rural revitalization finally. This paper discusses the restrictive factors and problems faced by the development of characteristic tourism towns in Northern Anhui, China, and explores the ideas and countermeasures for further development. 


\section{Literature Review}

\subsection{Concept and Characteristics of Characteristic Towns}

In fact, the formulation of characteristic town originates from the early strategy of small towns. In the early years, Fei Xiaotong (1996) proposed that small towns are a new type of transitional community between urban and rural areas, which has gone through the end of the people's commune period, the industrialization of rural areas in China, and the development of rural urbanization, although it has not completed the process of urbanization, it has basically departed from the nature of rural communities [5].The decision on several major issues in agriculture and rural areas put forward the development strategy of small towns and began to promote it throughout the country in 1998. Characteristic towns came into being gradually on the basis of the strategic development of small towns. Wang Boya et al. (2020) pointed out that the evolution of the concept of Chinese characteristic towns has also experienced three stages, namely, small towns in the traditional sense developed in the name of characteristic towns, characteristic towns represented by Zhejiang in the administrative sense, and characteristic towns that integrate production and living ecological spaces within 1 to 3 square kilometers and have characteristic industries gathering [6].

The practice of Characteristic Towns in Zhejiang Province has always been in the forefront of the country, and the characteristic towns we have built at this stage are the concepts that were first mentioned at the Yunqi Conference in Hangzhou in 2014. In 2015, Zhejiang Province promulgated the "Guiding Opinions of the People's Government of Zhejiang Province on Accelerating the Planning and Construction of Characteristic Towns", which proposed the concept of characteristic towns in Zhejiang Province for the first time, that is, "a development space platform relatively independent of the urban area and with clear industrial positioning, cultural connotation, tourism and certain community functions, which is different from administrative division units and industrial parks" [7]. On this basis, in the outline of the 13th Five-Year Plan for national economic and social development of the people's Republic of China in 2016, the national development and Reform Commission proposed to build a "characteristic town with distinctive industrial form, harmonious and livable beautiful environment, distinctive traditional culture, convenient and perfect facilities and services, and dynamic system and mechanism" [1]. Since then, it has set off a boom in the construction and research of characteristic towns in the country. Many scholars explained the characteristics of characteristic towns from different angles. Sheng Shihao et al. (2016) pointed out that the construction of characteristic towns is a form of industrial organization and an important practice to promote supplyside reform [8]. Zhou Xiaohong (2017) believed that the construction of characteristic towns are an urbanization model characterized by regional spatial reconstruction and growth factor agglomeration [9]. Wei Longbao et al (2016) considered that characteristic towns are the new driving force and innovation carrier of regional economic development, and summarized their characteristics into four points: "special and strong" industry, "organic combination" of functions, "small and beautiful" form, and "new and alive" mechanism [2].

\subsection{The Internal Relationship Between Characteristic Towns and Rural Revitalization}

Since the report of the 19th National Congress of the Communist Party of China put forwardthe rural vitalization strategy, General Secretary Xi Jinping once again stressed the importance of rural revitalization in his speech at the Fifth Plenary Session of the 19th Central Committee, and in order to achieve the goal, it is necessary to give priority to the development of agriculture and rural areas and comprehensively promote rural revitalization [10].As an important node of urban-rural integration development, the construction of characteristic towns is closely related to rural revitalization. Yao Shangjian (2016) pointed out that the problems and contradictions between rural and urban areas have become prominent with the acceleration of urbanization, and the establishment of characteristic towns that take into account industry and ecology will help solve the identity conflicts of towns outside the urban system, and become an important policy plan for relieving urban functions, promoting urban-rural integration and the strategic development of rural revitalization [11]. Wang Tianyu (2020) believed that there is a benign interaction between rural revitalization, the construction of Characteristic Towns and the development of small and medium-sized enterprises. The construction of characteristic towns plays an important role in focusing on industry, transferring rural surplus labor force and improving the development level of small and medium-sized enterprises. It is an effective carrier to realize the benign interaction between agricultural and rural modernization, industrialization and urbanization, and thus promoting rural revitalization and development [12]. Song Hong (2019), Xiong Zhengxian (2019) and Hou Yi (2020) stressed that the sustainable development of characteristic towns is an important guarantee for achieving the strategic goal of rural revitalization, an important engine for the linkage development of towns and villages in the rural revitalization strategy, a new growth pole for rural tourism, and an innovative path to achieve rural revitalization and targeted poverty alleviation [13-15].

Just like Wang Jingxin (2018) et al. said that rural development in China is in a new stage of building characteristic towns and beautiful villages together and promoting the reconstruction of rural revitalization into regional space and the pursuit of comprehensive values, we should grasp the important position of the construction of characteristic towns in the implementation of the rural revitalization strategy, take the synchronous planning and construction of characteristic towns and beautiful villages as the starting point, take rural revitalization as the focus, formulate more specific and feasible rural revitalization plans and promotion policies, and gradually realize the Chinese dream of great rejuvenation [16].

\subsection{The Construction Mode of Characteristic Towns}

Domesticandoverseas scholars have analyzed the construction mode or path of characteristic towns from different angles. Tan Ronghua (2018) took the characteristic towns in Sichuan Province as an example, divided the characteristic towns into tourism and leisure type, modern agriculture type, business logistics type, processing and manufacturing type, cultural creativity type, science and 
technology education type and other seven types, and explored the development model of characteristic towns of "industry + finance" [17]. Zhao Peipei (2016) analyzed the characteristics of the innovation of the construction mode of characteristic towns in Zhejiang Province, which is at the forefront of the construction of characteristic towns in the country, that is, the comprehensive construction plan that highlights the dual upgrading of industry and space, the supply-side reform and innovation that is in line with the market and reflects the planning, and the integrated design of the implementation and the whole process [18].Wei Rongrong (2017) believed that the PPP model is an inevitable choice for the construction of characteristic towns, and different financing paths can be selected according to the three stages of industrial development, which can achieve the sustainable development of characteristic towns [19]. Ji Weiwei (2020) took Dushan Town of Lu'an City as an example, and used empirical analysis to verify the feasibility of sustainable development of cultural tourism characteristic towns under the PPP model [20]. Xu Hong et al. (2019) took Yuanjia village in Shaanxi Province as an example and pointed out that the inclusive rural tourism poverty alleviation mechanism represented by the leadership implementation mechanism, fair participation mechanism, benefit sharing mechanism and guidance service mechanism is conducive to the development of the tourism economy of characteristic towns [21]. Rukhsana N. Badaet al. (2020) took Simla, India as an example, assessed the development of characteristic towns in mountainous areas and believed that the sustainable development of characteristic towns needed to balance the relationship between tourism growth and the protection of natural and cultural assets [22]. Akhtar Siddiqi (1993) emphasized the role of local government policy-making in the development of characteristic towns [23]. Griet Steel et al. (2019) discussed the development of small towns in subSaharan Africa based on qualitative and quantitative data from 10 different study sites, including Cameroon, Ghana, Rwanda, and Tanzania, showing that the diversification and commercialization of rural industries play a crucial role in the development of characteristic towns [24]. Zhang Qing (2015) believed that the construction modes of foreign characteristic towns mainly include scientific and technological characteristics, traditional industrial characteristics and cultural characteristics, of which the more representative ones include industrial transformation and upgrading mode, such as glass town in France; Scale effect model, such as Greenwich, USA. Give play to the circular economy model, such as the small town of Kalenberg in Denmark [25].

In addition, from the perspective of research objects, the existing research results are mainly concentrated in the central and eastern regions where the development of characteristic towns is relatively mature, especially in southern Jiangsu, Zhejiang and other regions, and there are not many studies on characteristic towns in the western region. As far as Anhui Province is concerned, the existing research is mainly concentrated in southern and central Anhui, and there is still a lack of research on Characteristic Towns in Northern Anhui. This paper will analyze the development status of characteristic tourism towns in Northern Anhui from the perspective of rural revitalization, and explore new ideas and strategies for building characteristic towns and promoting the development of Rural Revitalization Strategy in Northern Anhui.

\section{Overall Development of Characteristic Tourism Towns in Northern Anhui}

\subsection{Quantity Distribution}

In terms of regional division, Northern Anhui includes six prefecture-level cities of Huaibei, Bozhou, Fuyang, Huainan, Bengbu and Suzhou, one county-level city of Jieshou, and 17 counties including Suixi County, Guoyang County, Mengcheng County, Lixin County, Taihe County, Linquan County, Funan County, Yingshang County, Fengtai County, Shou County, Huaiyuan County, Wuhe County, Guzhen County, Xiao County, Yanshan County, Lingbi County, and Si County.According to the list of characteristic towns published by the National Development and Reform Commission and the official website of the Anhui Provincial Development and Reform Commission, there are 142 characteristic towns in Anhui Province, including 15 national-level characteristic towns and 127 provincial-level characteristic towns. Among them, there are 32 in northern Anhui, accounting for only $22.5 \%$ of the province's number, and the only national-level characteristic town is Guangwu Town, Jieshou City, Fuyang Cityby the end of 2020.

In 2020, 9 provincial-level characteristic towns in Anhui Province were selected as the top 50 towns with Chinese characteristics, ranking third in the country in terms of overall number, second only to Zhejiang Province (18) and Guangdong Province (11), including the digital town of Suzhou High-tech Zone and the health food town of Xiangshan District of Huaibei City. It is not difficult to see that the number of characteristic towns in northern Anhui is significantly less than that in central Anhui and southern Anhui.

\subsection{Specific Developments}

Northern Anhui has unique and rich natural and environmental resources. It not only has rich cultural tourism value. Moreover, the formation of its characteristics means that its operation and development have different emphases and characteristics, although each town is in the same area. Taking Guangwu Town, Jieshou City, Fuyang City, the only national characteristic town in northern Anhui as an example. Guangwu town has been a station and important town in the Central Plains since ancient times, with a history of more than 2,000 years. It is mainly characterized by cultural relics sites with profound historical and cultural accumulation and cultural landscape established based on natural landscapes, and is rich in renewable plastic resources, and the circular economy industrial park continues to grow and develop. It is the economic center north of Yinghe River in Jieshou City. Not only that, Guangwu Town was also selected as one of the "Top 100 Townships in Central China in 2018". Another example is the digital town of Suzhou High-tech Zone, with a planning area of 3.35 square kilometers, which is the core area of the current development of the digital industry in Suzhou High-tech Zone. It focuses on the development direction of the three major digital industries of basic, application and innovation, with the cloud computing industry as the core, the three major industries of digital cultural creativity, digital intelligent manufacturing and digital e-commerce as mutual support, focusing on building a basic cloud, platform cloud, and application cloud industry development model. It creates a complete digital economy industrial system by improving 
digital services and supporting service industries [26]. The health food town, located in Xiangshan District, Huaibei City, is a characteristic town integrating food processing, food culture and leisure tourism. It has a gathered food industry. There are 42 food processing enterprises and related supporting enterprises, 5 Chinese well-known trademarks and 8 provincial leading enterprises in agricultural industrialization in the town. In addition, the supporting facilities are complete, and the road grid bureau with "two vertical and six horizontal" roads as the main framework is basically formed, and the "nine links and one level" such as water, electricity, roads, communications, sewage pipe networks, natural gas, and heating are realized [27]. Shihe peony health town, Qiaocheng District, Bozhou City, integrates peony flower planting with traditional Chinese health culture to form a sports characteristic town. Bozhou is a famous capital of Chinese medicinal materials in China, famous for the cultivation and distribution of traditional Chinese medicine. Relying on the resources of China's medicinal material capital, it has planted more than 100,000 $\mathrm{mu}$ of Bo Bai peony, thus forming a health culture town characterized by traditional Chinese medicine planting, culture and Five-Animal Exercises [28].

Table 1 is the statistical table of the development of characteristic tourism towns in northern Anhui at the present stage. The author analyzes and summarizes their characteristics respectively.

Table 1. List of Characteristic Towns and statistics of characteristic points in Northern Anhui

\begin{tabular}{|c|c|c|c|}
\hline Number & Region & Name & Characteristic Points \\
\hline 1 & \multirow{6}{*}{$\begin{array}{l}\text { Huaibei } \\
\text { City (6) }\end{array}$} & Colorful agrotourism townin Lieshan District & $\begin{array}{l}\text { Fruit planting, fruit e-commerce sales demonstration, } \\
\text { agricultural tourism scenic spots }\end{array}$ \\
\hline 2 & & Pomegranate townin Lieshan District & Pomegranate planting and processing, tourism \\
\hline 3 & & "Sancai" cultural tourism town in Suixi County, & Industrial town, red tourist attraction \\
\hline 4 & & Canal culture town in Suixi County & A thousand-year-old canal historical and cultural town \\
\hline 5 & & Healthy food townin Xiangshan District & Food processing, food culture, leisure tourism \\
\hline 6 & & Agricultural tourismtown in Xiangshan District & $\begin{array}{c}\text { Aromatic plant planting, processing, research and } \\
\text { development and leisure tourism industry }\end{array}$ \\
\hline 7 & \multirow{6}{*}{$\begin{array}{l}\text { Bozhou } \\
\text { City (6) }\end{array}$} & $\begin{array}{l}\text { Traditional Chinese medicine e-commerce town } \\
\text { in Economic Development Zone }\end{array}$ & Cultivation of Chinese medicinal herbs, health tourism \\
\hline 8 & & Green fruit and vegetable town in Lixin County & $\begin{array}{l}\text { Fruit tree planting } \\
\end{array}$ \\
\hline 9 & & $\begin{array}{l}\text { Licang agricultural tourism townin Mengcheng } \\
\text { County }\end{array}$ & $\begin{array}{c}\text { "Rice and shrimp co-cultivation" ecological agriculture, } \\
\text { leisure tourism }\end{array}$ \\
\hline 10 & & Shihe peony health town in Qiaocheng District & $\begin{array}{l}\text { Chinese herbal medicine cultivation and culture, Five- } \\
\text { Animal Exercises }\end{array}$ \\
\hline 11 & & Gujing liquor town in Qiaocheng District & Liquor processing, liquor culture tourism \\
\hline 12 & & $\begin{array}{l}\text { Yimen Traditional Chinese Medicine Health } \\
\text { Town in Guoyang County }\end{array}$ & Traditional Chinese medicine cultivation and health culture \\
\hline 13 & \multirow{7}{*}{$\begin{array}{l}\text { Fuyang } \\
\text { City (7) }\end{array}$} & Guangwu Town in Jieshou City & Cultural sites, cultural landscapes \\
\hline 14 & & Aromatic town in Yingzhou district & Flower cultivation \\
\hline 15 & & $\begin{array}{l}\text { Bali river tourist style town in Yingshang } \\
\text { County }\end{array}$ & Tourist attractions, nature reserves \\
\hline 16 & & Huanggang Liuyi town in Funan County & $\begin{array}{c}\text { China's willow town, willow weaving industrial products } \\
\text { production industry }\end{array}$ \\
\hline 17 & & $\begin{array}{l}\text { Muyi fishing sports leisure town in Linquan } \\
\text { County }\end{array}$ & Sports and leisure \\
\hline 18 & & Baolong stone art town inYingquan District & Stone industry agglomeration area, "stone culture" tourism \\
\hline 19 & & Maji hair art town in Taihe County & Hair art culture industry \\
\hline 20 & \multirow[b]{2}{*}{$\begin{array}{l}\text { Huainan } \\
\text { City (2) }\end{array}$} & Bagongshan tofu town in Shou County & The birthplace of tofu, a tourist attraction \\
\hline 21 & & $\begin{array}{c}\text { Jiaogang lake hexiang town inMaoji Experiment } \\
\text { Zone }\end{array}$ & National wetland park, wetland cultural tourism \\
\hline 22 & \multirow{6}{*}{$\begin{array}{l}\text { Bengbu } \\
\text { City (6) }\end{array}$} & Agricultural trade town in Huaiyuan County & Agricultural markets \\
\hline 23 & & International football town in Bengshan District & Sports complex industry, sports brand owners \\
\hline 24 & & $\begin{array}{c}\text { Industrial design town in Economic } \\
\text { Development Zone }\end{array}$ & Industrial design industry cultivation base \\
\hline 25 & & New display town in High-tech Zone & Complete electronic information industry chain \\
\hline 26 & & $\begin{array}{l}\text { Hequan agricultural tourism town in Yuhui } \\
\text { District }\end{array}$ & Agricultural leisure tourism \\
\hline 27 & & Smart logistics town in Huaishang District & $\begin{array}{c}\text { The first batch of provincial logistics demonstration parks } \\
\text { in the province }\end{array}$ \\
\hline 28 & \multirow{5}{*}{$\begin{array}{l}\text { Suzhou } \\
\text { City (5) }\end{array}$} & Crispy Pear Town in Dangshan County & Crispy pear processing, pear blossom tourism \\
\hline 29 & & Canal Town in Sixian County & Intangible cultural heritage \\
\hline 30 & & Digital town in High-tech Zone & $\begin{array}{l}\text { Digital cultural creativity, digital intelligent manufacturing, } \\
\text { digital e-commerce }\end{array}$ \\
\hline 31 & & Equestrian town of Dangshan County & Ecotourism, leisure sports \\
\hline 32 & & $\begin{array}{c}\text { Intelligent terminal townin Ma'anshan Modern } \\
\text { Industrial Park }\end{array}$ & Intelligent terminal manufacturing, cultural tourism \\
\hline
\end{tabular}

Note: Table 1 is based on the information published by the National Development and Reform Commission and the official website of Anhui Province Characteristic Town. 


\section{Restrictive Factors and Problems Faced by the Development of Characteristic Tourism Towns in Northern Anhui}

In recent years, the northern Anhui has made outstanding achievements in excavating tourism culture and developing tourism towns. Due to its late start, its development is facing some restrictive factors and problems, which affect the further development of characteristic tourism towns. Its main manifestations are:

First, the business model is single and the cultural excavation level is shallow. At present, the demand of tourists for rural tourism is becoming stronger and stronger, while the rural tourism business model in northern Anhui is still dominated by family business, and its tourism resource integration is poor. There are multiple scattered business places in a tourism destination. In addition, the operators and service providers are mainly local residents, due to the lack of systematic management and service experience of local service providers and managers. As a result, local tourism resources have not been tapped in depth, which has greatly affected the tourism experience brought to tourists. Although there has been a trend of cultural and tourism integration in recent years, the model of tourist towns that deeply integrate local ethnic culture and tourism, such as Yuanjia Village in Xi'an, Shaanxi Province, is still rare in northern Anhui. There is no clear thinking, the imbalance of tourism products, the failure to grasp the main line of products, and the focus of integration is not strong, resulting in an imbalance in industrial development.

Second, the development foundation is relatively weak, and industrial products are not closely related. According to the survey, since most rural areas in Northern Anhui are far away from cities, the economy is based on traditional agriculture based on traditional planting, so relying on the existing agricultural foundation and cultivating modern agricultural products as the main industry is the main direction for realizing agricultural modernization. Optimizing the rural industrial structure, improving the quality of agricultural products and relying on high-quality, ecological and efficient agricultural products to win the market are important tasks for the development of characteristic tourism towns. The adjustment of industrial structure should also combine its own product resource advantages, make full use of its strengths and avoid its weaknesses, expand the industrial chain, and form a new industrial pattern with modern agricultural industry companies as the leader, the production, deep processing, sales and service of agricultural products, and the development of three-dimensional tourism culture by integrating tourism, play, and entertainment on the basis of the production and development of modern agricultural products. Tourists generally like to purchase characteristic agricultural products after leisure tourism in rural characteristic towns, take home and share with relatives and friends. However, at present, in the construction of rural characteristic towns in northern Anhui, the close connection between agricultural products and leisure tourism has not been considered to form a supporting regional industrial chain.

Third, the essence of cultural characteristics is not fully reflected, which needs to be deeply excavated. Characteristics are the soul of tourism and culture is the basis of characteristics. Only through the excavation of culture can we truly form the characteristics of a tourism destination. For example, during the construction of rural tourism, many characteristic towns mainly focus on fruit and vegetable picking for sightseeing or simple farmhouse fun, so that tourists go once and are unwilling to go for the second time. It simply caters to the public taste and excessively pursues commercial value, but ignores the core problem of "characteristics" in the construction of characteristic towns.

\section{Development Ideas and Countermeasures of Characteristic Tourism Towns in Northern Anhui}

\subsection{Give Full Play to the Resources with the Most Comparative Advantages and Take the Road of Characteristic Development}

The characteristic is the personality of the product under the premise of having a market and production conditions. Characteristics are differences, and differences are different here and elsewhere. The difference is the difference and uniqueness of this product compared with other products. It can be said that the basis for the existence of tourism is the difference in geographical conditions, natural scenery, social culture and different countries, nationalities and regions, as well as people's curiosity to pursue differences. Therefore, the construction and publicity of scenic spots in local characteristic tourist towns must pursue individuality, highlight differences, and highlight distinctive aspects.

To develop characteristic towns, the most important thing is to develop local resources with the most unique characteristics and comparative advantages, so as to form unique and competitive products required by the market and obtain better economic benefits. Each place has its own unique advantages, and the clean land and air in "remote" areas, characteristic natural resources and cultural landscapes are all advantages. In the process of developing characteristic tourist towns in northern Anhui, it is first necessary to look at the advantages and disadvantages dialectically, and be good at discovering and using its own advantages; The key is to have correct ideas, well-informed information, industrial development and product development to meet the needs of the market.

It is necessary to make full use of the natural and artificially created forest and vegetation environment, such as the natural and human environment such as mountain ecology, canyon ecology, grassland ecology, and natural lake ecology, and appropriately develop and do not know the agricultural planting areas and breeding areas to combine the ecological environment and agriculture to jointly develop agricultural ecological tourism, so as to achieve the purpose of selfcultivation that not only protects the ecology, but also enables tourists to fully enjoy the natural beauty [29].

Farmers are the main force in the construction of characteristic tourism towns, and they are also a way to show the culture of characteristic tourism towns in northern Anhui. During the construction of characteristic tourism towns in northern Anhui, it is necessary to respect the labor achievements of farmers. On the one hand, we should respect farmers' original habits and lifestyles, on the other hand, we should preserve the original ecological mark to the greatest extent. Attracting tourists through the unique local customs and culture is also an effective way to reflect the characteristics of characteristic tourism towns. 


\subsection{Make Leisure Tourism Related to Characteristic Industries and Products in Small Towns Closely}

The center of characteristic tourism towns is the agricultural industry, which is the foundation. Tourism is the tertiary industry and service industry based on agriculture, and it is also the inevitable product and result of the upgrading of industrial development. We should take tourism as the center, integrate the development of various industries in rural areas, make full use of the nature of products and extend the industrial chain of products as far as possible, that is, we should apply people's thinking mode of dividing primary industry, secondary industry and tertiary industry to the development of characteristic tourism towns, and consider the comprehensive development of three industries with the same resources, So as to improve the comprehensive benefits of the development of characteristic tourism towns. For example, farmers in Longquanyi, Chengdu used to grow peaches and only knew how to sell them. After a few years, they used the environment of Taoyuan to engage in tourism in the peach blossom season and made a lot of money. Further, they combine the processing of peach juice, preserved peach and peach wood tourist souvenirs, so that the comprehensive benefits of characteristic tourist towns can be developed.

\subsection{Excavate Deeply and Absorb Traditional Culture Fully to Create a Development Idea of Combining Culture with Tourism}

A problem of characteristic tourism towns in northern Anhui is the lack of embodiment of cultural essence. For example, when many characteristic towns carry out rural tourism construction, they mainly focus on fruit and vegetable picking experience sightseeing or simple farmhouse leisure tourism vacation mode, and lack the excavation of traditional culture. This lack of deep excavation design of traditional culture will lead to the decline of core competitiveness in the development of characteristic tourism towns. Therefore, it is necessary to dig deep into and make use of local characteristic resources, excavate local local culture, and actively introduce elements such as history, culture, and ethnicity. Then, how to combine the development of characteristic tourism towns with the excavation and protection of local intangible cultural heritage, and what are the contents of intangible cultural resources? Specifically, the content of intangible cultural resources can refer to the requirements of UNESCO for inclusion in the list of representative works of human intangible and oral cultural heritage. Intangible resources include: production processes such as various operas and related masks, props and clothes; dance, such as national festival dance and etiquette; music, such as all kinds of national folk music and appliance making technology; oral literature, such as myths, legends, epics, games and stories; all kinds of exquisite traditional crafts and handicrafts, such as knitting, weaving and dyeing, embroidery, carving, bamboo and rattan weaving, dough making, toy making and paper cutting [30]. It is necessary toprotect the local intangible cultural heritage vigorously, and carry out characteristic transformation of facilities and products in rural characteristic tourism towns. For example, martial arts schools around Shaolin Temple in Henan Province, acrobatics in Wuqiao County and dragon dancein Tongliang County of Chongqing Province have all formed sustainable development industries. They all make money by relying on traditional skills and culture. In this way, they earn more than those ways of making money by fighting for physical strength.

\subsection{Explore New Mode of "Internet PlusTourism" Actively}

At present, China's society has entered the information economy society, and smart tourism has been promoted continuously. The traditional offline tourism model can no longer meet people's requirements for high-quality tourism products and tourism experience. Now China has entered the information society, that is, the Internet plus era, and network life and network survival have penetrated into every aspect of people's lives. The intelligent development of rural tourism helps to realize the transformation and upgrading of tourism products, attract tourists to participate in the dissemination and promotion of tourism products, and improve the economic benefits of employment and tourism towns. Therefore, in the development of characteristic tourism towns in northern Anhui, it is necessary to make full use of the advantages of the Internet, combine cloud computing, cloud storage, Internet of things technology, virtual reality technology, big data, smart terminal technology and the development of rural tourism towns, and integrate them into every link of the six elements of "eating, living, traveling, traveling, shopping, and entertainment", establish a tourism information database of rural characteristic tourist towns, combine "online display" and "offline experience" closely, build a "cloud tourism" platform and form an Internet model for the development of rural tourist towns with "Internet plus tourism" in northern Anhui.

\section{References}

[1] Outline of the 13th five year plan for national economic and social development of the people's Republic of China[DB/OL].(2016)[2020-10-

15]http://www.xinhuanet.com//politics/2016lh/201603/17/c_1118366322_21.htm.

[2] Wei Longbao, Shi Xinjie. Some thoughts and suggestions on the construction of Characteristic Towns in Zhejiang [J]. Zhejiang Social Sciences, 2016 (3): 28-32.

[3] Liu Ruifang. On the functional orientation of rural characteristic tourism town under the background of Rural Revitalization [J]. Modern business, 2019, (10): 28-29.

[4] Xi Jinping. Win a decisive victory in building a well-off society in an all-round way and win the great victory of socialism with Chinese characteristics in the new era $[\mathrm{M}]$. On governing the country Beijing: Foreign Language Press, 2020.

[5] Fei Xiaotong. On the development of small towns in China [J]. China rural economy, 1996 (3): 3-5 + 10 .

[6] Wang Boya, Zhang Chewei, Cai Yifei. Re recognition of the positioning and function of Characteristic Towns -- an important carrier of urban-rural integrated development $[\mathrm{J}]$. Journal of Beijing Normal University (SOCIAL SCIENCE EDITION), 2020 (01): 140-147.

[7] Guiding opinions of Zhejiang Provincial People's Government on accelerating the planning and construction of characteristictowns[DB/OL].(2015)[2021-01-

03]http://www.zj.gov.cn/art/2015/5/4/art_32431_202183.html.

[8] Sheng Shihao, Zhang Weiming. Characteristic town: a form of industrial spatial organization [J]. Zhejiang Social Sciences, 2016, (03): 36-38. 
[9] Zhou Xiaohong. Industrial transformation and cultural reconstruction: the path of creating characteristic towns [J]. Nanjing Social Sciences, 2017 (04): 12-19.

[10] Key points ofCommunique of the 6th Plenary Session of the 19th CPC Central Committee [DB/OL]. (2020) [2021-0103]http://cpc.people.com.cn/n1/2020/1029/c16411331911575.html.

[11] Yao Shangjian. Characteristic town: role conflict and scheme adjustment -- Also on the policy issues of Rural Revitalization [J]. Exploration and contention, 2018, No. 346 (08): 86-92 + 145.

[12] Wang Tianyu. On the cultivation and development of Characteristic Towns under the background of Rural Revitalization Strategy -- Based on the combination and interaction analysis of characteristic towns, small and mediumsized enterprises and Rural Revitalization [J]. Henan Social Sciences, 2020,28 (07): 105-111.

[13] Song Hong, Gu Haiwei.Study on Influencing Factors of sustainable development of agricultural characteristic towns under the background of Rural Revitalization [J]. Northeast Agricultural Science, 2019,44 (02): 75-80.

[14] Xiong Zhengxian. Spatial reconstruction and Town Village interaction of Characteristic Towns under the background of Rural Revitalization -- Taking Zhusha ancient town and Qianhu Miao village in Guizhou as an example [J] Southcentral University for Nationalities, 2019, 39 (02): 118-122.

[15] Hou Yi, Jiang Juncheng. Research on Rural Revitalization Strategy and sustainable contribution of tourism characteristic towns to targeted poverty alleviation [J]. Discussion on modern economy, 2020 (08): 125-132.

[16] Wang Jingxin, Zhi Xiaojuan. China's Rural Revitalization and its regional spatial reconstruction -- the case, experience and future of revitalizing the countryside with the construction of Characteristic Towns and beautiful villages [J]. Journal of Nanjing Agricultural University: Social Science Edition, 2018, 18 (02): 17-26.

[17] Tan Ronghua, Du Kunlun. Research on the development model of "industry + finance" in characteristic towns [J], Southwest finance, 2018 (03): 3-9.

[18] Zhao Peipei, Ding Yuan. Analysis on the establishment and planning and design characteristics of Characteristic Towns in Zhejiang Province [J]. Planner, 2016 (12): 57-62.

[19] Wei Rongrong, Zou Xiaoyong. Research on PPP innovation support model for the development of characteristic towns [J].
Research on technology, economy and management, 2017, (010): 125-128

[20] Ji Weiwei, Research on sustainable development evaluation of tourism characteristic towns under PPP mode [D].Anhui University of architecture, 2020.

[21] Xu Hong, Wang Caicai Study on the mechanism of rural tourism getting rid of poverty and getting rich from the perspective of inclusive development -- the case enlightenment of Yuanjia village, Shaanxi Province [J] Exploration of economic issues, 2019, (006): 59-70

[22] Rukhsana N.BADAR,Sarika P.BAHADURE.Assessing tourism sustainability in hill towns: Case study of Shimla, India[J].Journal of Mountain Science,2020,17(09):2241-2261.

[23] Akhtar Siddiqi. Small town growth and development policy in Pakistan[J]. GeoJournal,1993,30(4):421-434.

[24] Griet Steel, Torben Birch-Thomsen, Ine Cottyn, Evelyn A. Lazaro, Hélène Mainet, Fulgence J. Mishili, P. van Lindert. Multi-activity, Multi-locality and Small-Town Development in Cameroon, Ghana, Rwanda and Tanzania[J]. The European Journal of Development Research,2019,31(1):12-33.

[25] Zhang Qing. Research on the protection and development of famous historical and cultural towns in Northern Anhui under the guidance of characteristic towns [D]. Anhui University of architecture, 2018

[26] Ding Hui. Suzhou high tech Zone digital town was successfully selected as a provincial characteristic town [EB/OL].(2019-0315) [2020-10-

14]http://www.suzhoufb.cn/htmls/suzhoukuaixun/shizhengku aixun/2019-03-15/24260.html.

[27] Huaibei Municipal Bureau. Health food town in Xiangshan District was selected as one of the top 50 towns with Chinese characteristics [EB/OL].(2020-08-19)[2021-0106]http://amr.ah.gov.cn/xwdt/dszc/143318021.html

[28] Zhong Hongxia .Bozhou, the world's capital of medicine, is the most healthy city [N]. Anhui Daily, April 14, 2020 (11).

[29] Kong Xiangzhi. Report on the prospects of agriculture, rural areas and farmers in China [M]. Beijing: China Times Economic Publishing House, 2005:273.

[30] Zhang Xiaoliang. Gold concept of rural characteristic economic $[\mathrm{M}]$. Chongqing: Chongqing University Press, 2006:166 